\title{
Ambulatório de oncologia de um hospital universitário: um estudo à luz da Metodologia Ergonômica para o Ambiente Construído (MEAC)
}

\section{Oncology clinic of a university hospital: a study based on Ergonomic Methodology for the Built Environment (EMBE)}

\author{
WANDERLEY, Flávio de Araújo \\ Universidade Federal de Pernambuco, Mestrando em Ergonomia \\ flaviowand@hotmail.com \\ LIMA, Tamires de Almeida Costa \\ Universidade Federal de Pernambuco, Mestranda em Ergonomia \\ tamires.acl90@outlook.com \\ VILLAROUCO, Vilma \\ UFPE - PPGDesign/ PPErgo-; UFC - PPGau+d; Dra. em Engenharia \\ vvillarouco@gmail.com
}

\begin{abstract}
RESUMO
O objetivo deste artigo foi realizar uma avaliação ergonômica do Ambulatório de Oncologia de um Hospital Universitário em Recife, por meio da aplicação da Metodologia Ergonômica para o Ambiente Construído (MEAC), proposta por Villarouco (2008). O estudo permitiu a avaliação do ambiente construído como um todo, além de considerar a percepção ambiental dos profissionais que lá exercem suas atividades. Após a análise dos dados, foi possível identificar vários problemas, principalmente relativos à acessibilidade, e sugerir soluções para a adequação do local às normas vigentes.
\end{abstract}

Ergonomia do ambiente, clínica oncológica, hospital universitário.

\begin{abstract}
This paper aims shows an ergonomic evaluation of the Oncology Clinic of a University Hospital in Recife, by applying the Ergonomic Methodology for the Built Environment (MEAC) proposed by Villarouco (2008). The study allowed the evaluation of the built environment considering the environmental perception of the professionals who perform their activities there. After data analysis, it was possible to identify several problems, mainly related to accessibility, and to suggest solutions for the adaptation of the place to the current norms.
\end{abstract}

Indoor ergonomics, oncology clinic, university hospital. 


\section{$17^{\circ}$ ERGODESIGN \& USIHC 2019 \\ PUC-Rio, 11 a 13 de dezembro \\ Rio de Janeiro, RJ, Brasil}

$17^{\circ}$ Ergodesign - Congresso Internacional de Ergonomia e Usabilidade de Interfaces Humano Tecnológica: Produto, Informações Ambientes Construídos e Transporte

$17^{\circ}$ USIHC - Congresso Internacional de Ergonomia e Usabilidade de Interfaces Humano Computador

\section{INTRODUÇÃO}

Com a descoberta de que a produtividade poderia ser melhorada através da manipulação de elementos que fazem parte da relação do usuário com o seu ambiente de trabalho (ETTINGER, 1964), os estudos sobre essa relação passaram a ganhar extrema relevância também como parte integrante da ergonomia, uma vez que a saúde e o bem-estar do trabalhador, são proporcionados em significativa parcela pelas variáveis nela envolvidas.

Hoje, o ambiente de trabalho deve não só considerar as exigências estruturais e culturais da organização, mas também se adaptar às necessidades dos seres humanos que com ela interagem (LIMA COSTA; VILLAROUCO, 2012). Assim, a Ergonomia foca no ser humano, nas suas capacidades e limitações, buscando sempre adaptar o trabalho a ele e melhorar o conforto dos locais em que desempenha suas tarefas (CIDADE, 2005).

Ao atender os requisitos ergonômicos, pode-se não apenas alavancar o conforto, a satisfação e o bem-estar desses seres humanos, mas também minimizar seus constrangimentos, suas cargas cognitiva, psíquica e física e os custos humanos para a empresa, além de otimizar a produtividade do sistema humano-tarefa-máquina. (KROEMER; GRANDJEAN, 2005; MORAES E MONT'ALVÃO, 1998).

Assim sendo, e entendendo que a Ergonomia busca promover meios para que o trabalhador desenvolva suas atividades de forma mais produtiva sem afetar seu bem-estar e sua saúde (SANTOS, 2016), o objetivo do presente estudo foi avaliar ergonomicamente o ambiente do Ambulatório de Oncologia de um Hospital Universitário na cidade do Recife, por meio da aplicação da Metodologia Ergonômica para o Ambiente Construído (MEAC), proposta por Villarouco (2008). Tal metodologia desenvolve uma abordagem ergonômica baseada em uma avaliação técnica do ambiente, aliada à percepção ambiental do usuário em relação ao espaço, a fim de elaborar um diagnóstico ergonômico e propor soluções para sanar os possíveis problemas encontrados.

\subsection{Ergonomia do Ambiente Construído}

Para Vasconcelos et al (2011), a Ergonomia é uma disciplina científica que estuda o relacionamento do indivíduo com seu trabalho, analisando a interação do trabalhador com os equipamentos que usa para desenvolver suas atividades laborais. Dessa forma, essa disciplina utiliza conhecimentos que vão desde a anatomia humana até os fatores psicológicos do indivíduo, visto que também considera os aspectos do comportamento dele no ambiente laboral.

Conforme definiu a Associação Internacional de Ergonomia (IEA, 2018):

Ergonomia (ou fatores humanos) é a disciplina científica relacionada com a compreensão das interações entre seres humanos e outros elementos de um sistema, e a profissão que aplica teoria, princípios, dados e métodos para projetar a fim de otimizar o bem-estar humano e o desempenho global do sistema. [...] A Ergonomia ajuda a harmonizar as coisas que interagem com as pessoas em termos de necessidades, habilidades e limitações das pessoas. 


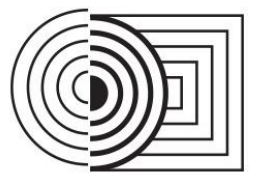

\section{$17^{\circ}$ ERGODESIGN \& USIHC 2019 \\ PUC-Rio, 11 a 13 de dezembro \\ Rio de Janeiro, RJ, Brasil}

$17^{\circ}$ Ergodesign - Congresso Internacional de Ergonomia e Usabilidade de Interfaces Humano Tecnológica: Produto, Informações Ambientes Construídos e Transporte

$17^{\circ}$ USIHC - Congresso Internacional de Ergonomia e Usabilidade

de Interfaces Humano Computador

Uma vez que é dentro das organizações que o trabalhador passa a maior parte do seu tempo, é necessário que sejam promovidas ações que procurem alavancar a saúde e o bemestar desses profissionais, evitando possíveis quedas de produtividade e favorecendo 0 desenvolvimento de suas competências, pois são considerados a força motriz essencial na diferenciação estratégica de uma empresa, seja ela pública ou privada (FRANÇA, 2010; HORTA et al, 2012).

Assim, a Ergonomia do Ambiente Construído ou Ergonomia Ambiental configura uma vertente que utiliza os aspectos sociais, psicológicos, culturais e organizacionais como ponto de partida para avaliar a relação do homem com o ambiente. Essa avaliação compreende três elementos fundamentais: os aspectos técnicos e materiais, que englobam a concepção espacial, o layout, os conceitos dimensionais, o mobiliário, os materiais de revestimento e o conforto ambiental; os aspectos organizacionais, que englobam os recursos humanos, as normas e os procedimentos que disciplinam a organização do trabalho; e os aspectos psicológicos, que englobam a percepção do usuário, as fronteiras dos espaços, a comunicação humana e a estética (VASCONCELOS et al, 2011).

Nesta direção, a Ergonomia do Ambiente Construído transporta seu foco para a adaptabilidade e a conformidade dos ambientes às tarefas que são desenvolvidas neles, utilizando ferramentas da antropometria, da psicologia ambiental, da ergonomia cognitiva e da metodologia ergonômica, além de alguns conceitos do conforto térmico, acústico e lumínico, para compor a grade de preocupações que fazem parte do desenvolvimento de ambientes ergonomicamente adequados (VASCONCELOS et al, 2011).

\subsection{Os Hospitais Universitários}

Os hospitais universitários são centros de formação de recursos humanos e de desenvolvimento de tecnologia para a área de saúde. A efetiva prestação de serviços à população possibilita o aprimoramento constante do atendimento e a elaboração de protocolos técnicos para as diversas patologias. Isso garante melhores padrões de eficiência, à disposição da rede do Sistema Único de Saúde (SUS).

Além disso, os programas de educação continuada oferecem oportunidades de atualização técnica aos profissionais de todo o sistema de saúde.

Os hospitais universitários apresentam grande heterogeneidade quanto à sua capacidade instalada, incorporação tecnológica e abrangência no atendimento. Todos desempenham papel de destaque na comunidade onde estão inseridos. (MEC, 2018)

\section{METODOLOGIA}

O presente artigo se classifica como uma pesquisa exploratória de abordagem qualitativa e cunho descritivo, que realizou uma avaliação ergonômica, em julho de 2019, do Ambulatório de Oncologia de um Hospital Universitário localizado na cidade do Recife. Os ambientes estudados incluíram a Recepção, a Sala de Espera, a Sala de Infusão de Quimioterapia, o Posto de Enfermagem e os banheiros masculino e feminino dos pacientes.

Para o desenvolvimento deste estudo, foi utilizada a Metodologia Ergonômica para o Ambiente Construído (MEAC), proposta por Villarouco (2008), em sua totalidade. Tal metodologia é composta por cinco etapas gerais, sendo as três primeiras referentes à avaliação 


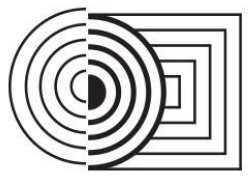

\section{$17^{\circ}$ ERGODESIGN \& USIHC 2019 \\ PUC-Rio, 11 a 13 de dezembro \\ Rio de Janeiro, RJ, Brasil}

$17^{\circ}$ Ergodesign - Congresso Internacional de Ergonomia e Usabilidade

de Interfaces Humano Tecnológica: Produto, Informações Ambientes

Construídos e Transporte

$17^{\circ}$ USIHC - Congresso Internacional de Ergonomia e Usabilidade

de Interfaces Humano Computador

física do ambiente; a quarta referente ao entendimento da percepção do usuário sobre o espaço com que ele interage; e a quinta referente ao diagnóstico ergonômico e às respectivas recomendações para adequação do ambiente.

Na primeira etapa, a Análise Global do Ambiente, foram realizados a observação geral do local, os registros fotográficos e entrevistas com seus usuários. Na segunda etapa, a Identificação da Configuração Ambiental, foram levantados e registrados os dados do ambiente físico (dimensionamentos, obtenção das plantas baixas e de layout), dos postos de trabalho e das condições ambientais (conforto térmico, acústico e lumínico) e a acessibilidade. Na terceira etapa, a Avaliação do Ambiente em Uso, foi observado todo o desenvolvimento das atividades dos usuários no ambiente, para avaliar o quanto as configurações atuais do local podem ser um facilitador ou não dessas atividades.

Na quarta etapa, a Percepção Ambiental do Usuário, foi realizada uma análise das expectativas e impressões de uma amostra de 20 profissionais sobre o ambiente com que eles interagem diariamente. Estes foram escolhidos aleatoriamente de um universo de 30 profissionais, entre médicos, enfermeiros, técnicos / auxiliares de enfermagem e auxiliares administrativos, que trabalham no respectivo Ambulatório. Para isso, foi aplicada a ferramenta Constelação de Atributos, idealizada por Moles (1968). E, na última etapa, foram cruzadas as informações coletadas na primeira fase de análise física do ambiente com os achados da percepção dos usuários, sendo por fim elaborado o diagnóstico ergonômico do Ambulatório, acompanhado das respectivas recomendações de adequação às normas vigentes, à melhoria do desempenho e às necessidades dos usuários.

\section{O ESTUDO DE CASO}

\subsection{Análise Global do Ambiente}

O Hospital Universitário a que se refere este estudo foi fundado em 1979 e está localizado na cidade do Recife/PE. É um hospital de referência para atendimentos de média e alta complexidade da rede de saúde do Sistema Único de Saúde (SUS), que tem como públicoalvo os pacientes referenciados de outros serviços e a demanda própria oriunda das diversas especialidades ambulatoriais para tratamentos avançados e cirurgias nas diversas modalidades clínicas.

O Ambulatório de Oncologia está situado no $3^{\circ}$ andar do Bloco E do respectivo Hospital e é distribuído em dezenove ambientes, funcionando de segunda a sexta-feira, das 7 h30 às 19h. Possui uma equipe multiprofissional com plantonistas (regime de 12h) e diaristas (regime de $6 \mathrm{~h}$ e $8 \mathrm{~h}$ ), sendo seu quadro composto por sete médicos especialistas em Oncologia, seis enfermeiras assistenciais, uma enfermeira gerente do serviço, uma nutricionista, uma psicóloga, uma assistente social, seis técnicas de enfermagem, dois recepcionistas, dois técnicos administrativos, dois auxiliares de serviços gerais e um porteiro, além de receber periodicamente residentes e acadêmicos de Enfermagem, que dedicam ao serviço de $30 \mathrm{~h}$ a $60 \mathrm{~h}$ semanais.

As atividades desenvolvidas no Ambulatório de Oncologia são: consultas médicas e consultas e agendamentos de enfermagem; atendimento e acompanhamento psicológico, nutricional e de serviço social; atendimento semanal de pulsoterapia (reumatologia e dermatologia); realização de curativos em feridas tumorais; manutenção de cateteres em 
pacientes que já concluíram o tratamento quimioterápico; infusão de quimioterapia (quimioterápicos, anticorpos monoclonais, hormonioterapia, terapia hematológica); e atendimento de urgências e emergências oncológicas dos pacientes com tratamento quimioterápico em andamento.

O serviço do Ambulatório de Oncologia segue as normas e diretrizes específicas do Ministério da Saúde; a NR 32, que estabelece as diretrizes para proteção à saúde dos trabalhadores nos serviços de saúde; a RDC no 220/2004 - ANVISA, regulamento técnico de funcionamento dos Serviços de Terapia Antineoplásica; e a RDC oㅜ 50/2002 - ANVISA, regulamento técnico para planejamento, elaboração e avaliação de projetos físicos de estabelecimentos assistenciais de saúde.

Após a observação geral do Ambulatório, o aspecto geral que se tem é de um ambiente limpo, porém apresentando má conservação da estrutura, dos equipamentos e do mobiliário; iluminação deficiente, acústica aceitável e temperatura com variações entre os ambientes.

\subsection{Identificação da Configuração Ambiental}

As condições físico-ambientais do espaço foram identificadas por meio dos dados coletados e da planta baixa (Figura 1) do Ambulatório de Oncologia, obtida através da Divisão de Infraestrutura e Logística do Hospital. As áreas em destaque na planta baixa se referem às áreas analisadas neste artigo, mencionadas anteriormente.

Figura 1 Planta baixa do Ambulatório de Oncologia de um Hospital Universitário do Recife.

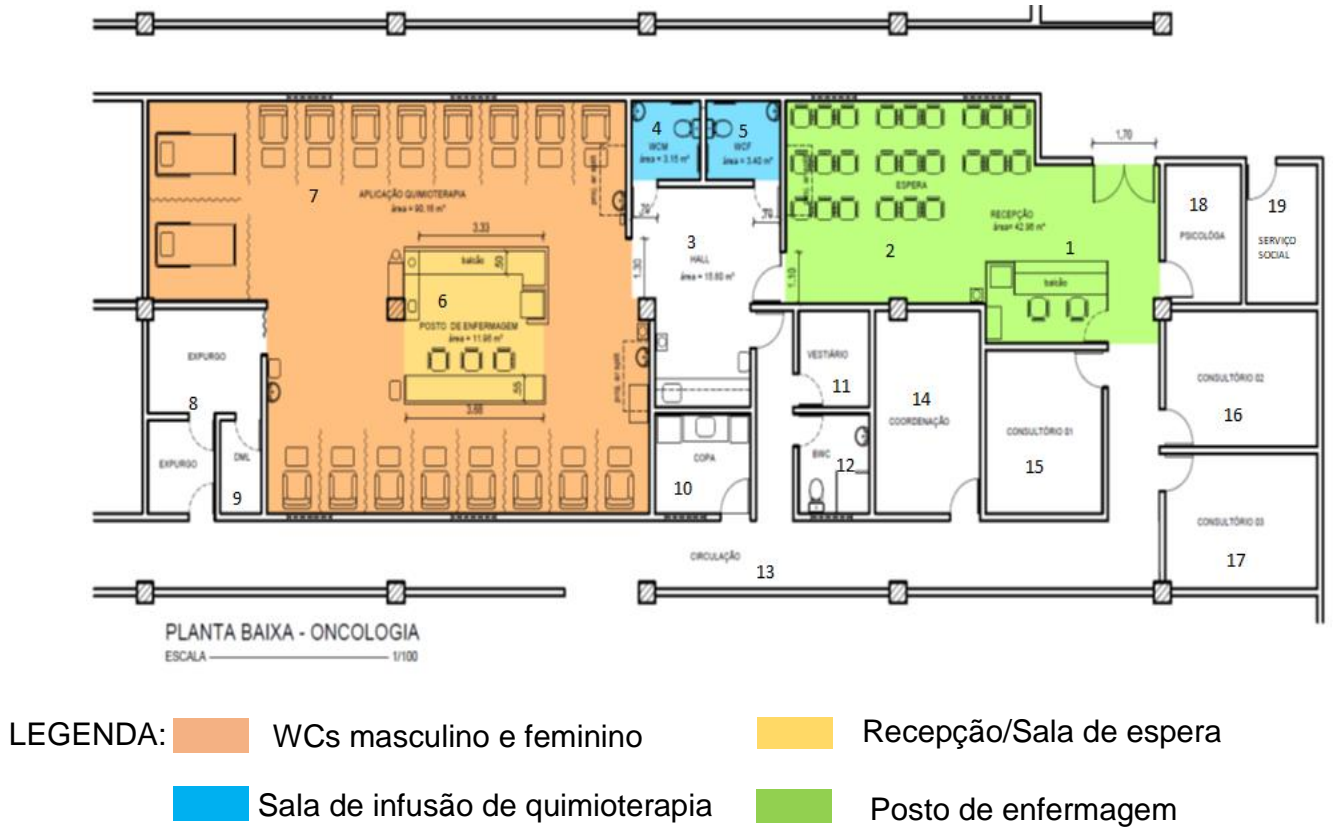

Fonte: Adaptada da Divisão de Infraestrutura e Logística do Hospital

Em geral, o Ambulatório possui piso vinílico em placas na cor bege, paredes com pintura acrílica semi-brilho de cores claras (bege/verde), teto com forro removível branco e lâmpadas 


\section{$17^{\circ}$ ERGODESIGN \& USIHC 2019}

PUC-Rio, 11 a 13 de dezembro

Rio de Janeiro, RJ, Brasil $17^{\circ}$ Ergodesign - Congresso Internacional de Ergonomia e Usabilidade de Interfaces Humano Tecnológica: Produto, Informações Ambientes Construídos e Transporte

$17^{\circ}$ USIHC - Congresso Internacional de Ergonomia e Usabilidade

de Interfaces Humano Computador

fluorescentes / LED frias. Na Recepção (Figura 2), há um balcão de atendimento com gavetas, duas cadeiras, dois computadores, uma impressora, um ventilador e um armário.

Figura 2 Balcão de atendimento da Recepção.

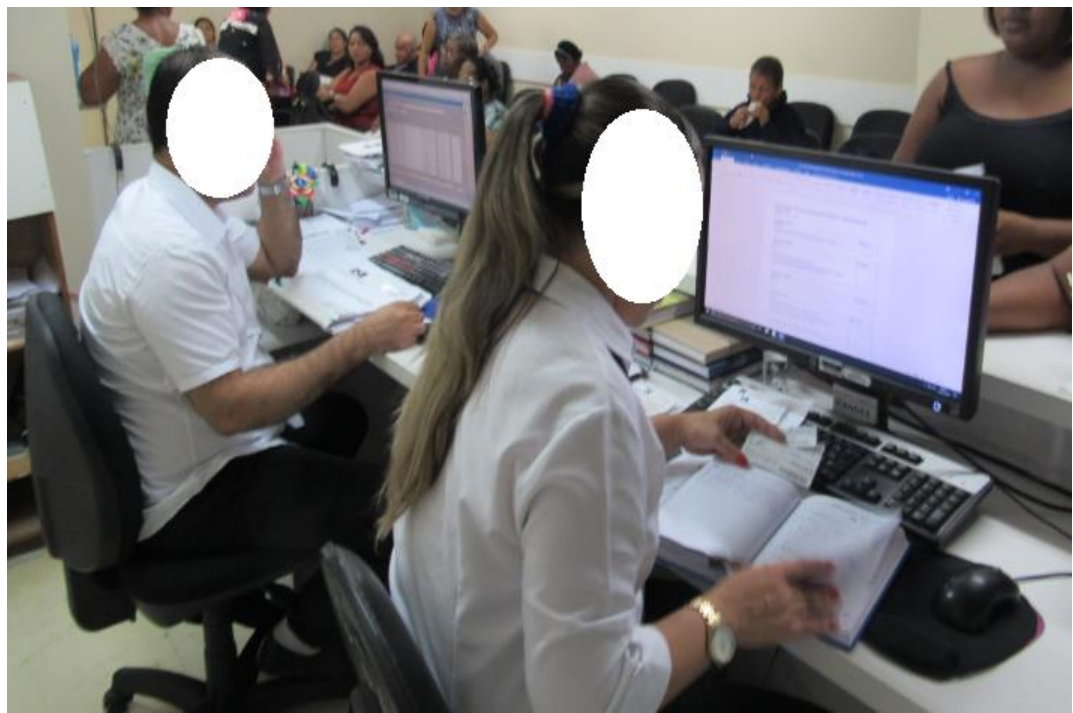

Fonte: autores (2019)

A Sala de Espera (Figura 3) comporta 24 pacientes sentados, tem um condicionador de ar tipo split, com potência de 18.000 btus, uma TV de 24 polegadas, suporte para álcool em gel, caixa de sugestões/reclamações, uma lixeira, um bebedouro e local para café e chá.

Figura 3 Sala de Espera dos pacientes.

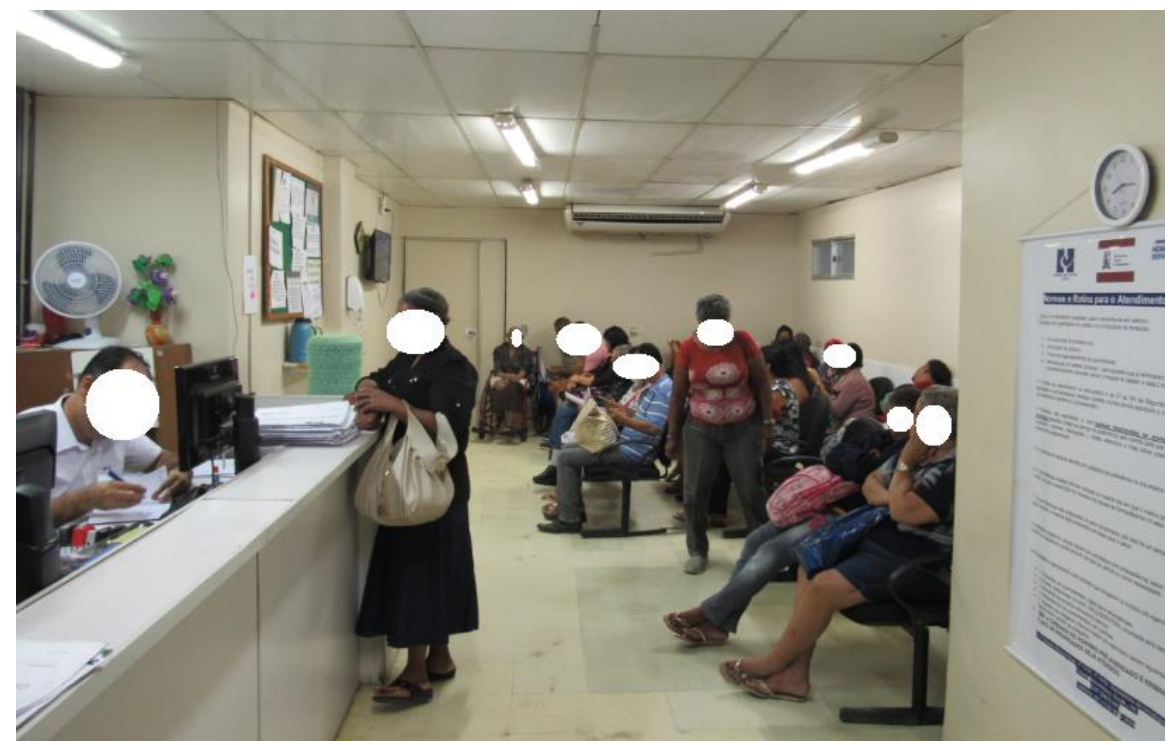

Fonte: autores (2019) 
$17^{\circ}$ ERGODESIGN \& USIHC 2019

PUC-Rio, 11 a 13 de dezembro

Rio de Janeiro, RJ, Brasil $17^{\circ}$ Ergodesign - Congresso Internacional de Ergonomia e Usabilidade de Interfaces Humano Tecnológica: Produto, Informações Ambientes Construídos e Transporte

$17^{\circ}$ USIHC - Congresso Internacional de Ergonomia e Usabilidade

de Interfaces Humano Computador

Já no Posto de Enfermagem (Figura 4), há duas bancadas, sendo uma para preparo e administração de medicamentos e outra para a organização do trabalho dos enfermeiros, contendo um computador e três cadeiras. No mesmo espaço ainda há uma pia e uma geladeira.

Figura 4. Posto de Enfermagem.

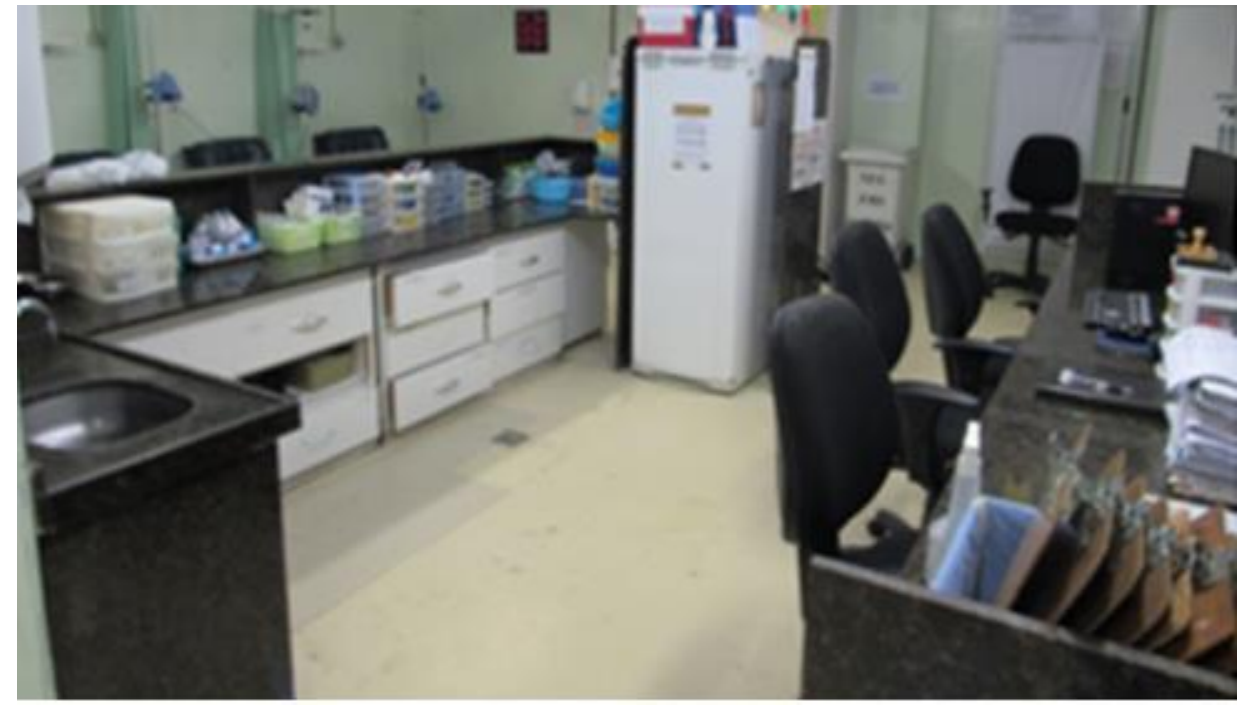

Fonte: autores (2019)

$\mathrm{Na}$ Sala de Infusão de Quimioterapia (Figura 5), existem dezesseis poltronas e dois leitos disponíveis para o tratamento quimioterápico, dois aparelhos de ar-condicionado tipo split, com potência de 58.000 e 60.000 btus respectivamente, três pias com sabão, papel toalha e álcool gel, um som e uma TV, que visam distrair os pacientes e os acompanhantes durante o atendimento.

Figura 5 Sala de Infusão de Quimioterapia.

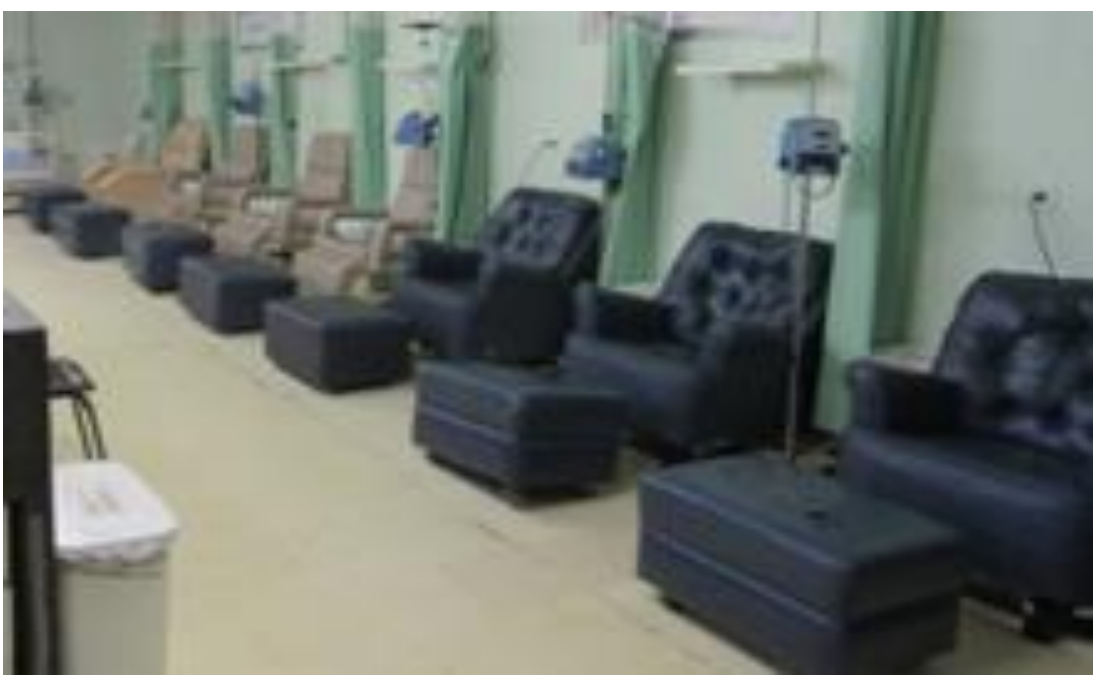

Fonte: autores (2019) 


\section{$17^{\circ}$ ERGODESIGN \& USIHC 2019}

PUC-Rio, 11 a 13 de dezembro

Rio de Janeiro, RJ, Brasil $17^{\circ}$ Ergodesign - Congresso Internacional de Ergonomia e Usabilidade de Interfaces Humano Tecnológica: Produto, Informações Ambientes Construídos e Transporte

$17^{\circ}$ USIHC - Congresso Internacional de Ergonomia e Usabilidade

de Interfaces Humano Computador

Em relação às Normas Técnicas, foi considerada a NBR 9050/2015 como parâmetro para a avaliação dos aspectos de acessibilidade. Isso permite afirmar que a entrada principal (Figura 6), por onde todos os usuários (pacientes, acompanhantes e os diversos profissionais) têm acesso ao serviço, possui problemas de acessibilidade e de segurança: a porta tem 1,70 m de largura, é pesada, não possui mola aderente ao chão, tem puxador redondo, sem sinalização de "puxe e empurre" e, no lado externo, existe uma longarina de espera que invade a área da porta, podendo causar acidentes e dificultando o acesso das pessoas à Recepção. Além disso, o piso possui ondulações com vários pontos danificados, o que aumenta o risco de acidentes.

Figura 6. Porta de entrada do Ambulatório de Oncologia.

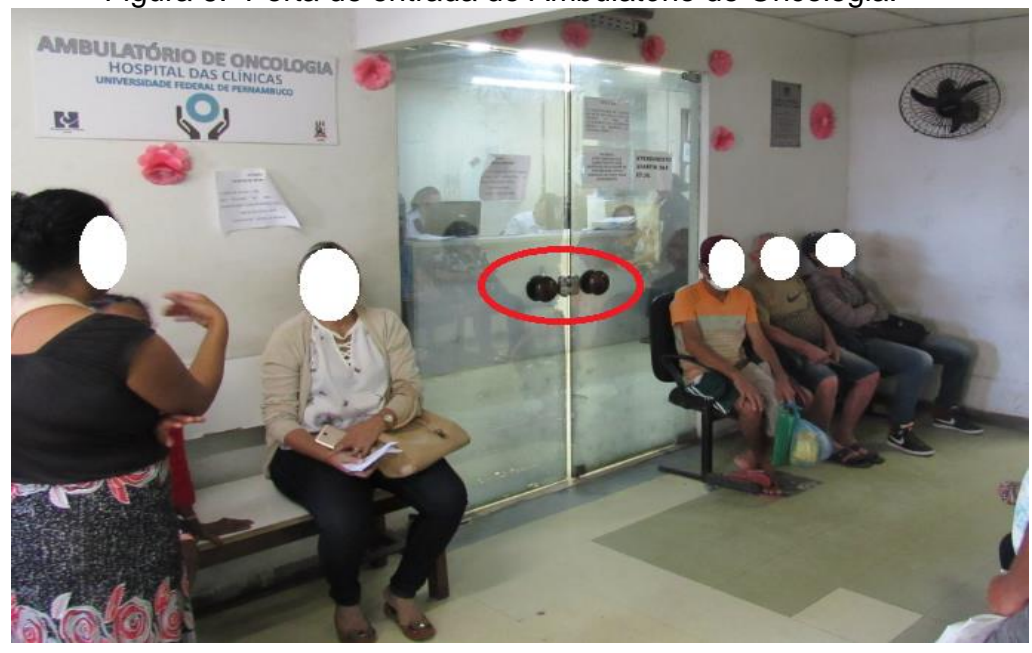

Fonte: autores (2019)

Nos banheiros dos pacientes (Figuras 7 e 8), a acessibilidade é ainda mais comprometida e não atende a maior parte das especificações exigidas pela NBR 9050/2015 para sanitários.

Figura 7 . Banheiro dos pacientes (masculino).

Figura 8 . Banheiro dos pacientes (feminino).
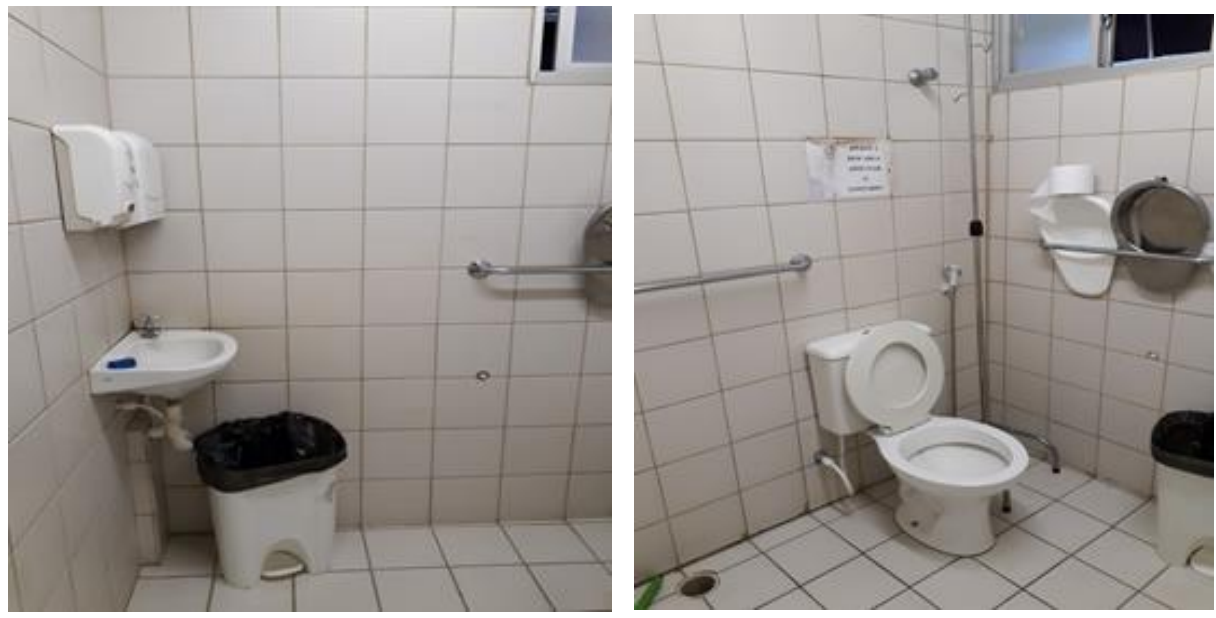

Fonte: autores (2019) 


\section{$17^{\circ}$ ERGODESIGN \& USIHC 2019}

PUC-Rio, 11 a 13 de dezembro

Rio de Janeiro, RJ, Brasil $17^{\circ}$ Ergodesign - Congresso Internacional de Ergonomia e Usabilidade de Interfaces Humano Tecnológica: Produto, Informações Ambientes Construídos e Transporte

$17^{\circ}$ USIHC - Congresso Internacional de Ergonomia e Usabilidade de Interfaces Humano Computador

As portas dos banheiros possuem 0,70 $\mathrm{m}$ de largura, impedindo seu uso por cadeirantes, já que a norma exige uma largura de no mínimo 0,80 m; há ralo dentro da área de transferência, o que é desaconselhado pela NBR 9050/2015; os dispensadores de sabonete líquido e de papel toalha estão mais altos que a faixa de alcance indicada pela norma (de 0,80 $\mathrm{m}$ a 1,20 m); as aparadeiras e o papel higiênico ficam em cima de uma das barras de apoio, inutilizando-a, além de também ficarem fora da faixa de alcance; e o piso não é antiderrapante.

Em relação às barras de apoio, em nenhum dos banheiros há barra vertical na parede lateral, como exigido; a barra de apoio da parede de fundo está muito afastada horizontalmente da caixa acoplada, que deveria iniciar $0,30 \mathrm{~m}$ antes do eixo da bacia, em direção à parede lateral; todas as barras estão acima de $0,75 \mathrm{~m}$ do piso, como a NBR 9050/2015 exige; as barras possuem 0,60 m de comprimento, não 0,80 m como deveriam; a porta abre para fora, porém não tem puxador horizontal no lado interno, como especificado na norma; e também não há dispositivo de emergência em nenhum dos banheiros.

A área para rota de fuga (corredor de circulação) está sinalizada, porém com vários obstáculos, principalmente a presença de vários armários. O final da rota de fuga é na porta do acesso principal na qual há vários problemas de acessibilidade e segurança, como vimos anteriormente. O local do extintor está sinalizado, porém não há nenhum extintor neste local ou em outra área do setor. (Figura 9)

Figura 9 Rota de fuga e local para extintor de incêndio.

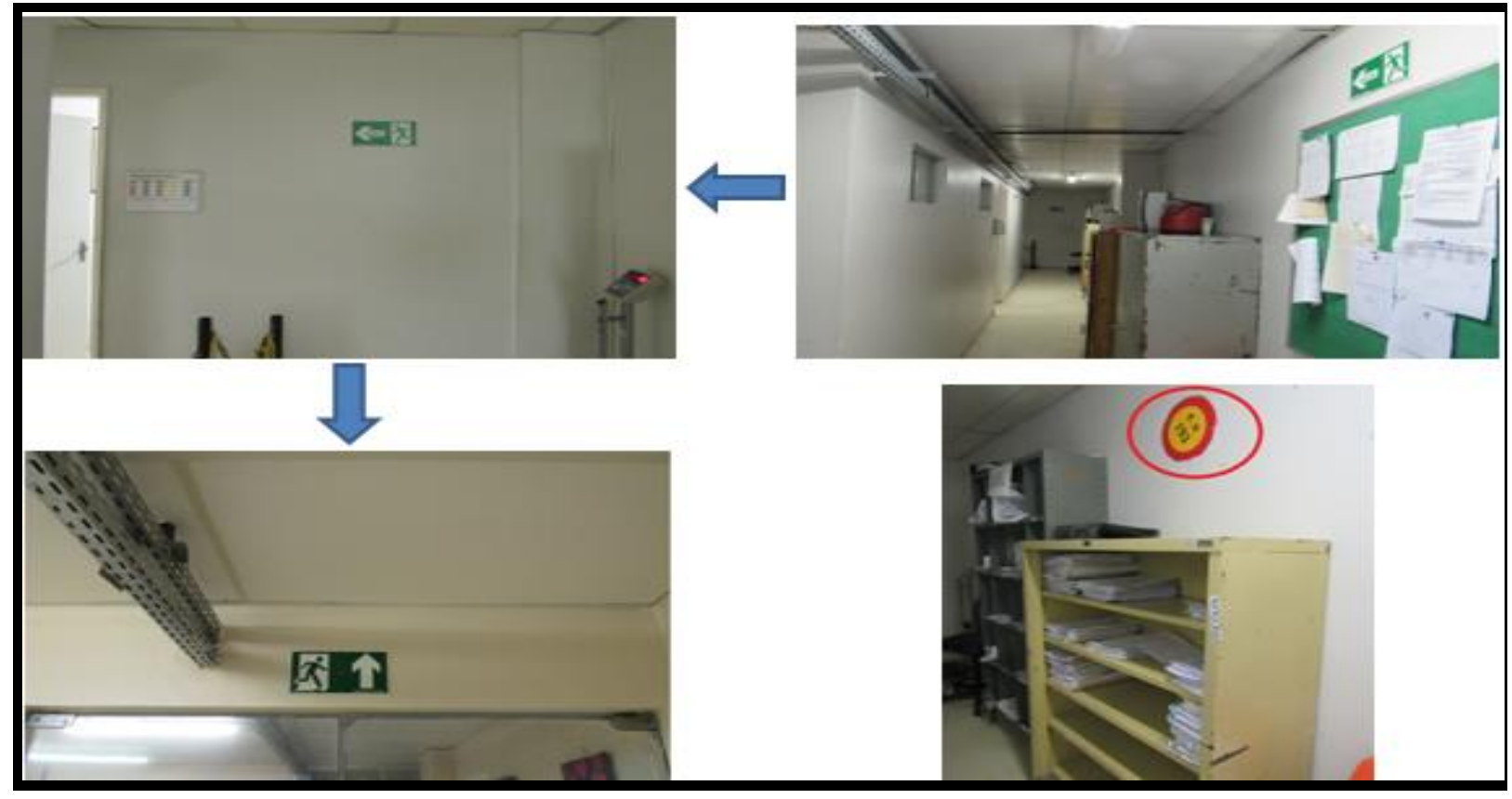

Fonte: autores (2019)

Já para a avaliação do conforto ambiental (iluminância, temperatura e ruídos), foram definidos sete pontos para medição: P1 e P2 - Recepção; P3 e P4 - Posto de Enfermagem; P5 e P6 - Poltronas da Sala de Infusão de Quimioterapia e P7 - Leito da Sala de Infusão de Quimioterapia, como mostrados na Figura 10. 


\section{$17^{\circ}$ ERGODESIGN \& USIHC 2019}

PUC-Rio, 11 a 13 de dezembro

Rio de Janeiro, RJ, Brasil $17^{\circ}$ Ergodesign - Congresso Internacional de Ergonomia e Usabilidade de Interfaces Humano Tecnológica: Produto, Informações Ambientes Construídos e Transporte

$17^{\circ}$ USIHC - Congresso Internacional de Ergonomia e Usabilidade de Interfaces Humano Computador

Para medir o nível de iluminância, foi utilizado o aplicativo Lux Meter para celular e os resultados foram comparados com os níveis indicados pela norma NHO 11/2018 (indicada na NR-17, vs. out'2018).

Figura 10 Pontos para avaliação dos confortos lumínico, acústico e térmico.

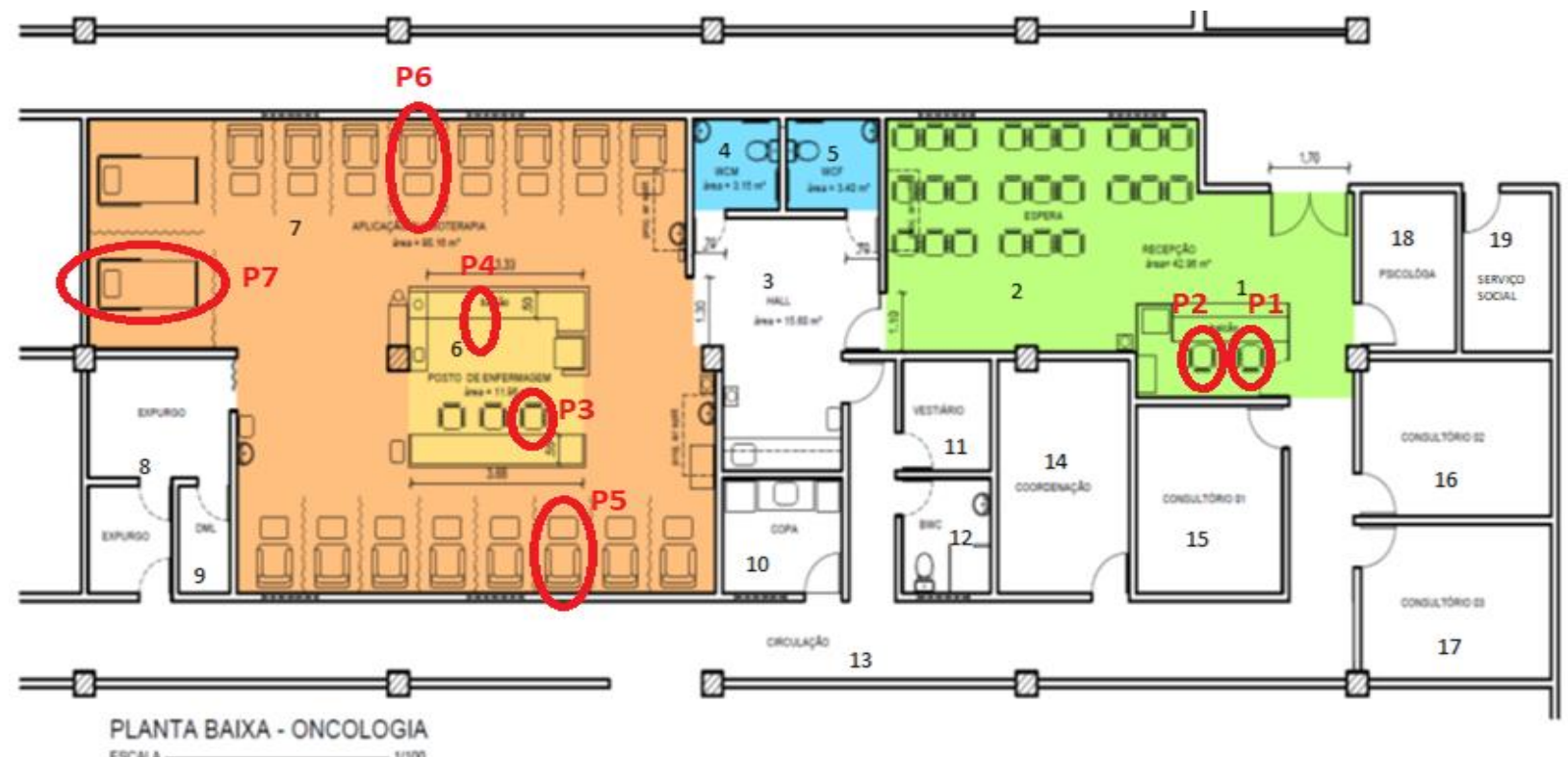

Fonte: autores (2019)

Foi observado que em todos os pontos avaliados, em horários diferentes, a iluminação não estava em conformidade com a norma. Um dos locais com valores muito abaixo do recomendado foram as poltronas da quimioterapia. Dessa forma, é importante destacar que nestes ambientes, onde são realizados os procedimentos de infusão de quimioterapia, a iluminação tem papel relevante na qualidade dos procedimentos realizados pelos profissionais de saúde (Quadro 1).

Quadro 1 Dados do conforto lumínico.

\begin{tabular}{|c|c|c|c|c|}
\hline PONTO & $\begin{array}{c}(\text { LUX) } \\
09: 00 \mathrm{H}\end{array}$ & $($ LUX) - 17:00H & NHO 11/2018 & LOCAL \\
\hline 1 & 124 & 115 & 300 & RECEPÇÃO \\
\hline 2 & 203 & 284 & 300 & RECEPÇÃO \\
\hline 3 & 313 & 314 & 500 & POSTO DE ENFERMAGEM \\
\hline 4 & 240 & 257 & 500 & POSTO DE ENFERMAGEM \\
\hline 5 & 62 & 94 & 500 & POLTRONA QUIMIOTERAPIA \\
\hline 6 & 156 & 77 & 500 & POLTRONA QUIMIOTERAPIA \\
\hline 7 & 142 & 102 & 500 & LEITO QUIMIOTERAPIA \\
\hline
\end{tabular}

Para avaliar o conforto acústico, foram analisadas as medições do ruído interno utilizando o aplicativo Sound Meter para celular e os dados foram comparados com os níveis 
$17^{\circ}$ ERGODESIGN \& USIHC 2019

PUC-Rio, 11 a 13 de dezembro

Rio de Janeiro, RJ, Brasil $17^{\circ}$ Ergodesign - Congresso Internacional de Ergonomia e Usabilidade de Interfaces Humano Tecnológica: Produto, Informações Ambientes Construídos e Transporte

$17^{\circ}$ USIHC - Congresso Internacional de Ergonomia e Usabilidade de Interfaces Humano Computador

indicados pela ABNT NBR 10.152/2000 (Quadro2). Todos os ambientes analisados também não estavam em conformidade com a respectiva norma. Os pontos da recepção que foram avaliados estavam com valores mais elevados do que o que a norma indica. Isso se deve provavelmente ao grande fluxo de pessoas neste ambiente.

Quadro 2 Dados do conforto acústico.

\begin{tabular}{|c|c|c|c|c|}
\hline PONTO & $\begin{array}{c}(\mathrm{dB})- \\
09: 00 \mathrm{H}\end{array}$ & $\begin{array}{c}(\mathrm{dB})- \\
17: 00 \mathrm{H}\end{array}$ & NBR 10.152 & LOCAL \\
\hline 1 & 75,0 & 76,1 & $35-45$ & RECEPÇÃO \\
\hline 2 & 68,0 & 70,8 & $35-45$ & RECEPÇAिO \\
\hline 3 & 64,3 & 63,3 & $35-45$ & POSTO DE ENFERMAGEM \\
\hline 4 & 65,2 & 67,4 & $35-45$ & POSTO DE ENFERMAGEM \\
\hline 5 & 63,4 & 64,2 & $35-45$ & POLTRONA QUIMIOTERAPIA \\
\hline 6 & 62,4 & 65,1 & $35-45$ & POLTRONA QUIMIOTERAPIA \\
\hline 7 & 61,6 & 63,7 & $35-45$ & LEITO QUIMIOTERAPIA \\
\hline \multicolumn{3}{|c}{ Fonte: autores (2019) }
\end{tabular}

Por último, para avaliar o conforto térmico foi utilizado o aplicativo Thermometer para celular e os dados foram comparados com os níveis indicados pela NR 17 Ministério do Trabalho (1996). Mais uma vez, os ambientes avaliados estavam em desacordo com a norma, como demonstrado no Quadro 3.

Quadro 3 Dados do conforto térmico.

\begin{tabular}{|c|c|c|c|c|}
\hline PONTO & $\begin{array}{c}\left({ }^{\circ} \mathrm{C}\right)- \\
09: 00 \mathrm{H}\end{array}$ & $\begin{array}{c}\left({ }^{\circ} \mathrm{C}\right)- \\
17: 00 \mathrm{H}\end{array}$ & NR 17 & LOCAL \\
\hline 1 & 26 & 25 & $20-23$ & RECEPÇÃO \\
\hline 2 & 26 & 25 & $20-23$ & RECEPÇÃO \\
\hline 3 & 25 & 24 & $20-23$ & POSTO DE ENFERMAGEM \\
\hline 4 & 25 & 24 & $20-23$ & POSTO DE ENFERMAGEM \\
\hline 5 & 25 & 24 & $20-23$ & POLTRONA QUIMIOTERAPIA \\
\hline 6 & 25 & 24 & $20-23$ & POLTRONA QUIMIOTERAPIA \\
\hline 7 & 25 & 24 & $20-23$ & LEITO QUIMIOTERAPIA \\
\hline
\end{tabular}

Fonte: autores (2019)

\subsection{Avaliação do Ambiente em Uso}

Na Recepção são admitidos os pacientes, agendadas as consultas, realizado o encaminhamento dos pacientes para as consultas e para as quimioterapias, e organizados os prontuários. Em razão da grande demanda diária, o ambiente torna-se inadequado e barulhento. O layout é inadequado para a permanência dos pacientes e dos acompanhantes, pois as cadeiras são insuficientes e algumas encontram-se quebradas. Além disso, o espaço frontal entre as cadeiras é de apenas $0,40 \mathrm{~m}$ e o lateral de apenas $0,50 \mathrm{~m}$, insuficientes para a circulação inclusive de pessoas sem órtese, visto que a NBR 9050/2015 indica que a circulação mínima deve ser de 0,60 m, comprometendo gravemente a acessibilidade.

Após a identificação na Recepção, o paciente é orientado a entrar no Posto de Enfermagem com o prontuário em mãos. Lá são realizadas as checagens dos exames 


\section{$17^{\circ}$ ERGODESIGN \& USIHC 2019}

PUC-Rio, 11 a 13 de dezembro

Rio de Janeiro, RJ, Brasil $17^{\circ}$ Ergodesign - Congresso Internacional de Ergonomia e Usabilidade de Interfaces Humano Tecnológica: Produto, Informações Ambientes Construídos e Transporte

$17^{\circ}$ USIHC - Congresso Internacional de Ergonomia e Usabilidade

de Interfaces Humano Computador

laboratoriais e a consulta de enfermagem, para identificação de queixas clínicas ou de sinais de alerta que impossibilitem a realização do tratamento no dia. Se todas as pré-condições estiverem de acordo, o paciente inicia a quimioterapia prevista.

No Posto de Enfermagem, a equipe multidisciplinar compartilha o mesmo espaço para o desempenho de suas atividades (Figura 11). Na bancada de trabalho, os móveis são despadronizados e precários, e sua organização varia de acordo com cada profissional e com a demanda do serviço.

Figura 11. Equipe multidisciplinar no Posto de Enfermagem.

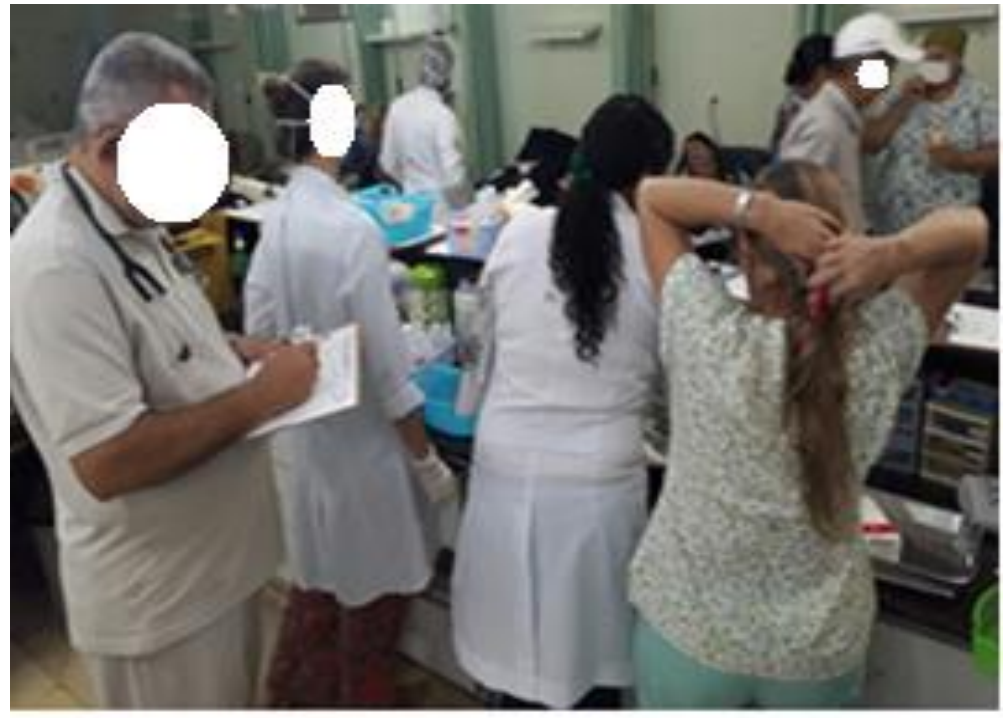

Fonte: autores (2019)

Figura 12 . Balcão de preparo das medicações.

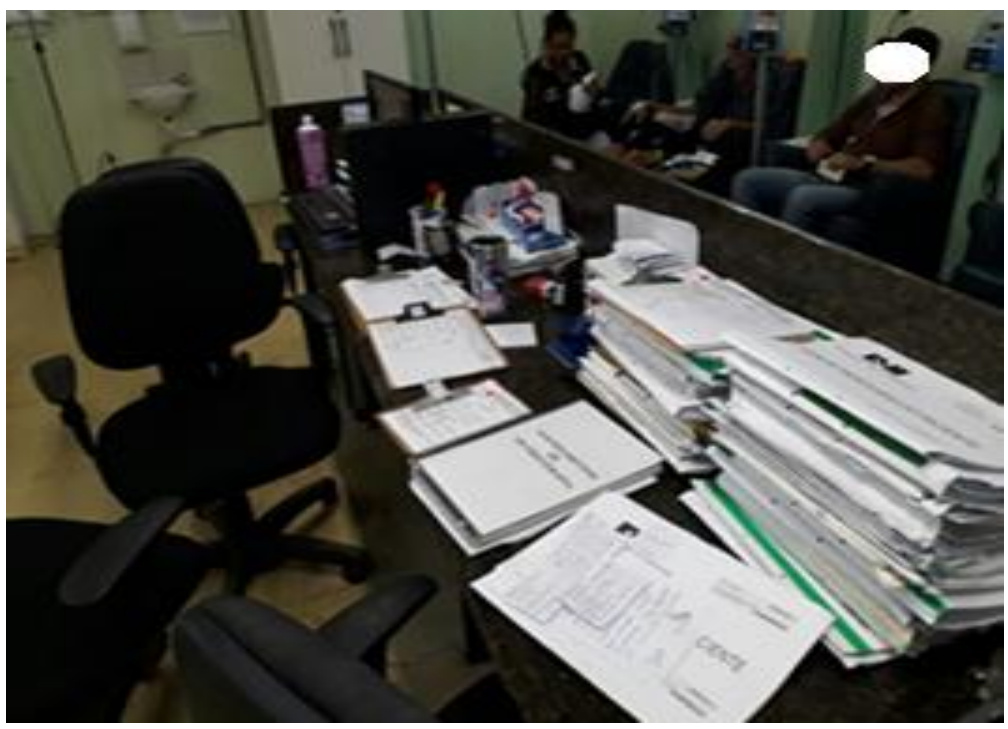

Fonte: autores (2019) 
Figura 13 . Bancada de trabalho do Posto de Enfermagem.

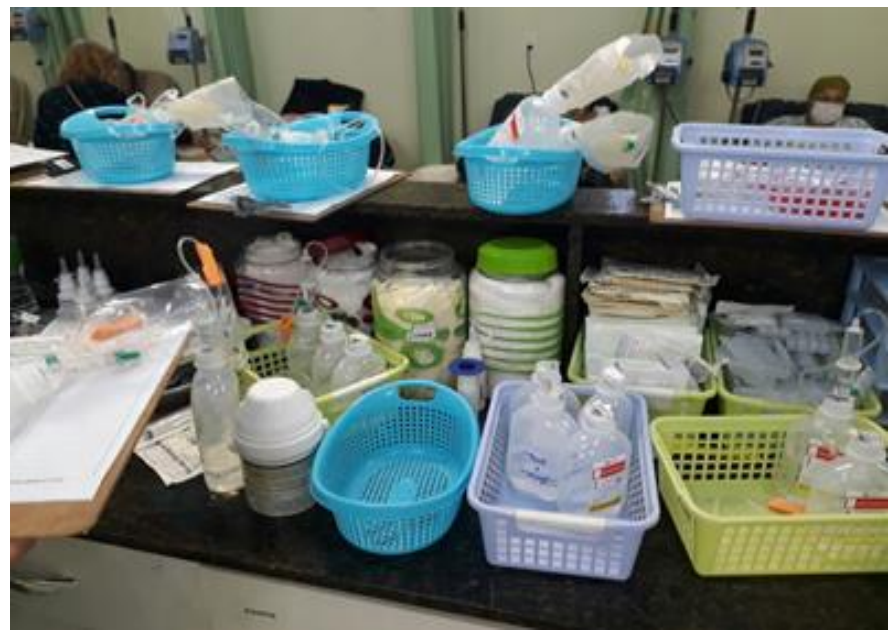

Fonte: autores (2019)

O balcão onde se preparam as medicações é pequeno para a realização de todas atividades relacionadas, inclusive os quimioterápicos, uns dos mais importantes para o setor (Figura 12). Alguns gaveteiros se encontram quebrados e o armazenamento dos materiais utilizados é feito em cestas plásticas. A falta de espaço para dispor a quantidade de prontuários utilizados faz com que sejam empilhados ao longo do dia, o que favorece a desorganização (Figura 13). Além disso, muitos materiais de uso pessoal (como garrafas com água, estojos e bolsas) ficam dispostos embaixo da bancada principal, junto com materiais médico-hospitalares.

Figura 14 . Poltronas da Sala de Infusão de Quimioterapia.

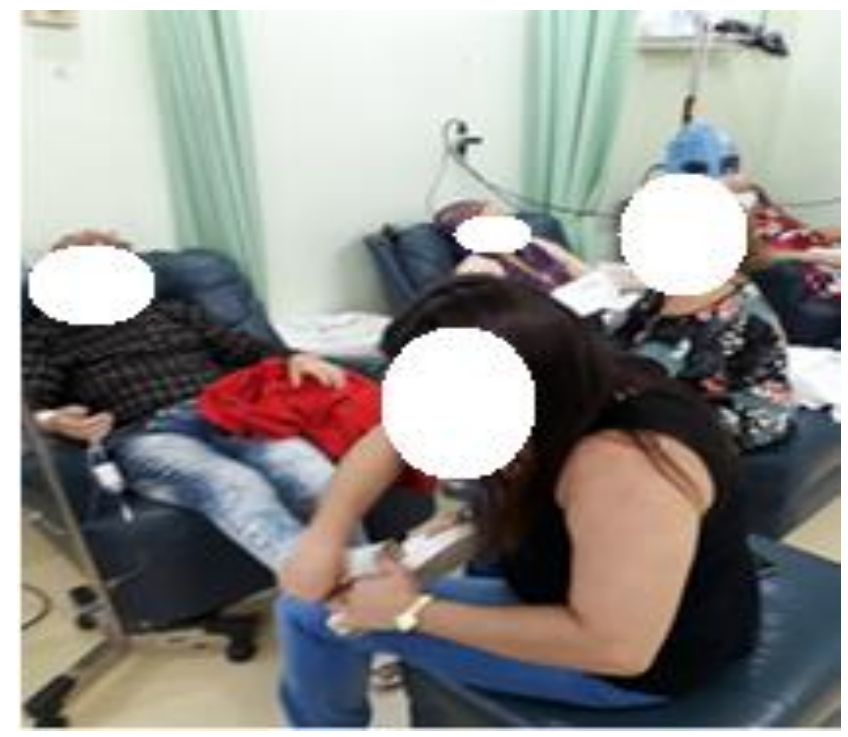

Fonte: autores (2019) 
$\mathrm{Na}$ Sala de Infusão de Quimioterapia, devido à falta de espaço entre as poltronas $(0,50$ m), as cortinas de separação comumente não são acionadas, gerando falta de privacidade.

As poltronas são desconfortáveis para os pacientes e não há cadeiras para os acompanhantes, fazendo-os utilizar como assento o apoio para os pés dos pacientes, o que passa a dificultar a circulação dentro da Sala e a aplicação das medicações nos pacientes pela equipe de enfermagem (Figura 14). Ressalte-se a obrigatoriedade dos acompanhantes para os pacientes em tratamento.

Pelo pouco espaço, convivem com muita proximidade as lixeiras com resíduos contaminados posicionadas entre as poltronas, os equipamento de suporte contendo bomba de infusão com quimioterapia, além de diversos fios expostos sobre o chão. O piso é escorregadio e apresenta inúmeras áreas danificadas, com quebras e desníveis que dificultam a acessibilidade, principalmente dos pacientes cadeirantes e daqueles que são transportados em macas.

\subsection{Percepção Ambiental do Usuário}

A etapa de análise da percepção do usuário pode ser considerada uma das mais fundamentais na avaliação do ambiente construído. De acordo com Villarouco (2008), um ponto importante da avaliação do ambiente construído é a percepção do usuário, pois é o usuário quem mais sofre com todos os impactos das sensações que um ambiente pode gerar.

Para esse estudo, foi aplicada a ferramenta Constelação de Atributos, idealizada por Moles em 1968. Essa ferramenta permite a compreensão da consciência psicológica do usuário em relação ao espaço que ocupa. A representação gráfica é composta por um núcleo, ou seja, o objeto de estudo, e "estrelas" que representam os atributos.

A distância entre os atributos e o núcleo representa a distância psicológica e determina o grau de importância de cada atributo para o usuário (VASCONCELOS; VILLAROUCO; SOARES, 2009).

Inicialmente, para a construção da Constelação, foram realizadas duas perguntas: uma referente ao espaço ideal, com a associação de ideias voltadas para as características espontâneas; e o espaço real, associando a ideias a partir de características induzidas. $\mathrm{Na}$ figura abaixo, foi avaliada a imagem simbólica do indivíduo frente ao ambiente ideal de um Ambulatório de Oncologia, por meio da pergunta: "Quando você pensa em um Ambulatório de Oncologia, que ideias ou imagens vem à sua mente?"

Assim, na percepção do ambiente ideal pelos participantes, uma maior quantidade de profissionais de saúde foi o atributo mais citado. A importância de uma equipe multidisciplinar e com profissionais suficientes para a demanda reflete esse desejo. Além disso, questões como iluminação adequada, disposição de medicamentos e insumos em quantidade suficiente, limpeza e atendimento humanizado refletem o desejo de um ambiente estruturado e adequado para um melhor atendimento e melhores condições para a realização do trabalho. 


\section{$17^{\circ}$ ERGODESIGN}

\& USIHC 2019

PUC-Rio, 11 a 13 de dezembro

Rio de Janeiro, RJ, Brasil $17^{\circ}$ Ergodesign - Congresso Internacional de Ergonomia e Usabilidade de Interfaces Humano Tecnológica: Produto, Informações Ambientes Construídos e Transporte

$17^{\circ}$ USIHC - Congresso Internacional de Ergonomia e Usabilidade de Interfaces Humano Computador

Figura 15 . Constelação de Atributos para o Ambulatório de Oncologia ideal.

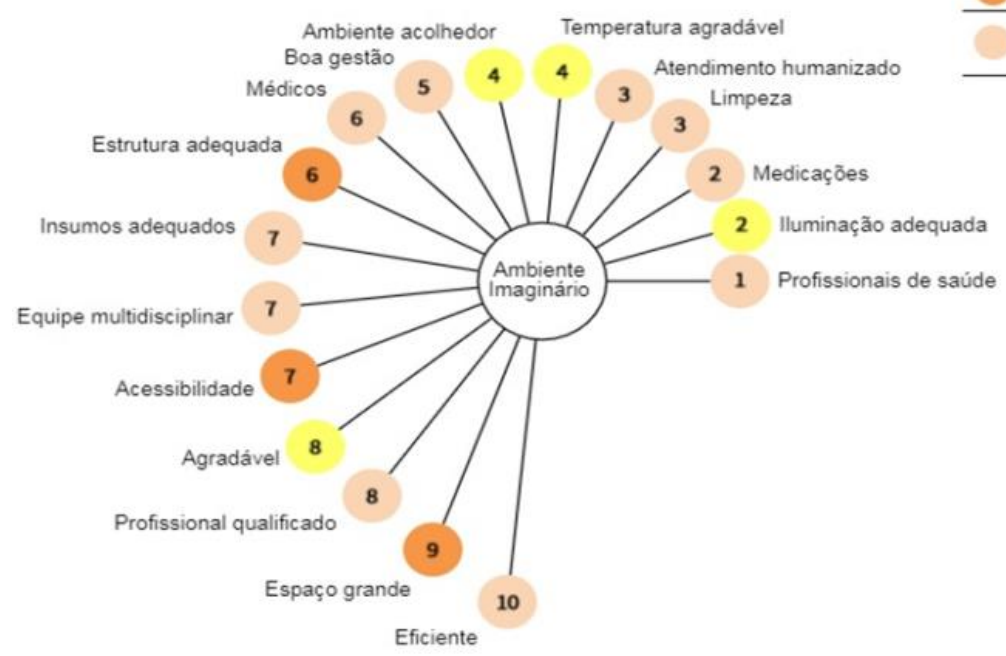

\begin{tabular}{ll}
\multicolumn{1}{c}{ Legenda } \\
\hline CONFORTO AMBIENTAL \\
\hline INSTALAÇÕES \\
\hline QUESTÕES \\
ORGANIZACIONAIS \\
\hline
\end{tabular}

Fonte: autores (2019)

$\mathrm{Na}$ avaliação do ambiente real, a pergunta foi: "Quando você pensa neste Ambulatório de Oncologia, que ideias ou imagens vem à sua mente?"

Figura 16 .Constelação de Atributos para o Ambulatório de Oncologia real.

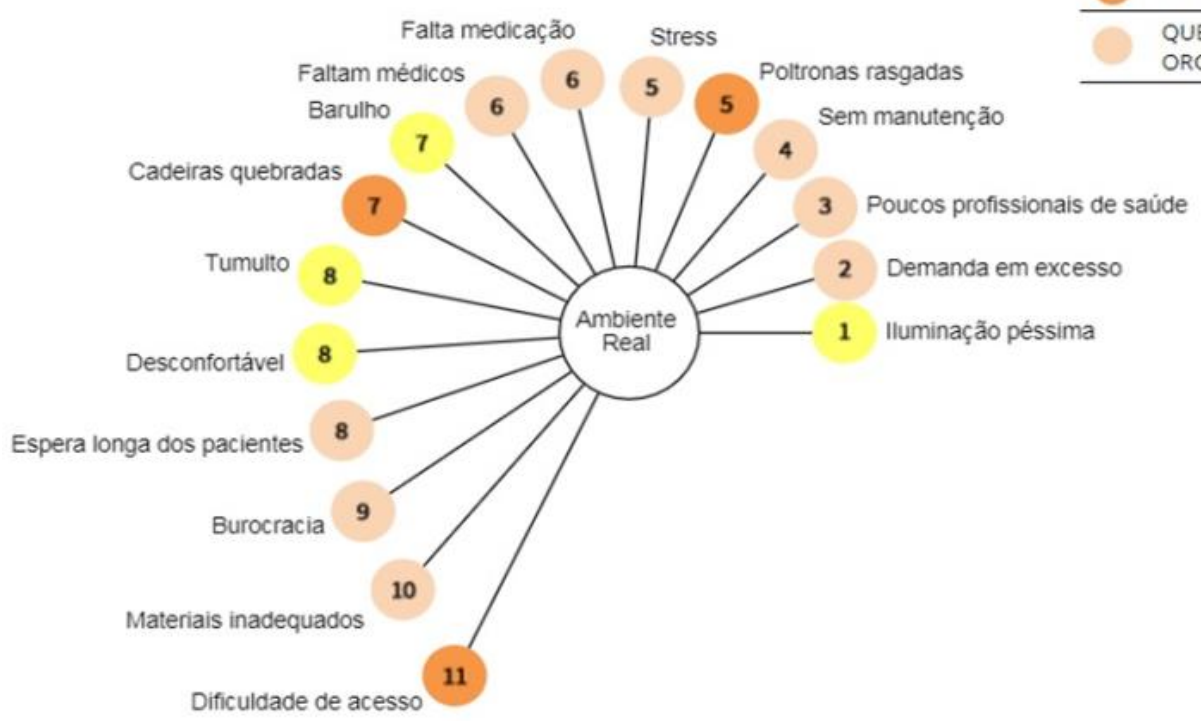

Legenda ONFORTO AMBIENTAL INSTALAÇÕES QUESTÕES ORGANIZACIONAIS

Fonte: autores (2019) 


\section{$17^{\circ}$ ERGODESIGN \& USIHC 2019 \\ PUC-Rio, 11 a 13 de dezembro \\ Rio de Janeiro, RJ, Brasil}

$17^{\circ}$ Ergodesign - Congresso Internacional de Ergonomia e Usabilidade de Interfaces Humano Tecnológica: Produto, Informações Ambientes Construídos e Transporte

$17^{\circ}$ USIHC - Congresso Internacional de Ergonomia e Usabilidade de Interfaces Humano Computador

$\mathrm{Na}$ Constelação de Atributos do ambiente real, percebeu-se que a iluminação péssima foi o atributo mais citado. Os entrevistados o apontaram como um dos atributos mais relevantes, em virtude da boa iluminação ser essencial para a realização de suas atividades diárias. Atributos relacionados a questões organizacionais como demanda em excesso, poucos profissionais de saúde e falta de manutenção refletem a necessidade de uma melhor estruturação e organização do setor para alavancar a qualidade do serviço prestado e a satisfação desses profissionais na realização de suas tarefas.

\section{DIAGNÓSTICO ERGONÔMICO DO AMBIENTE E RECOMENDAÇÕES}

Diante da análise de todos os dados coletados, pôde-se concluir que o espaço físico destinado ao Ambulatório de Oncologia não comporta a demanda existente nem está adequado ao tipo de atividade ali desenvolvida. Torna-se imprescindível a readequação da estrutura física e das questões organizacionais, de forma que acolham o fluxo diário de atendimentos. Outro aspecto importante é o layout dos ambientes, que apresenta pontos críticos, principalmente em relação à circulação e acessibilidade, considerando o perfil dos pacientes (idosos e cadeirantes) que circulam diariamente nos diversos ambientes do Ambulatório.

A partir dos problemas identificados ao analisar os dados levantados pelas medições, observações e entrevistas, construiu-se, abaixo, um quadro com o diagnóstico, ponto a ponto, e suas respectivas recomendações, com o intuito de sanar ou minimizar tais problemas:

Quadro 4 Diagnóstico e recomendações para o Ambulatório de Oncologia.

\begin{tabular}{|c|c|}
\hline DIAGNÓSTICO & RECOMENDAÇÃO \\
\hline $\begin{array}{l}\text { Espaço físico incompatível com a } \\
\text { demanda existente }\end{array}$ & $\begin{array}{l}\text { Reorganizar o trabalho e redefinir a demanda diária de acordo com a } \\
\text { estrutura física existente. }\end{array}$ \\
\hline Layout inadequado & $\begin{array}{l}\text { Readequar o layout atendendo as condições de circulação, acessibilidade e } \\
\text { segurança dos usuários. }\end{array}$ \\
\hline $\begin{array}{l}\text { Postos de trabalho incompatíveis } \\
\text { com os seus usuários }\end{array}$ & $\begin{array}{l}\text { Postos de trabalho mais amplos, adequados para as tarefas realizadas e } \\
\text { reguláveis para comportar os diversos perfis de profissionais. }\end{array}$ \\
\hline $\begin{array}{l}\text { Condições de conforto ambiental } \\
\text { inadequadas (iluminação, ruído e } \\
\text { temperatura) }\end{array}$ & $\begin{array}{l}\text { Readequar a iluminação, a temperatura e os ruídos do ambiente às normas } \\
\text { existentes, em especial a iluminação, pela importância para a realização das } \\
\text { tarefas. }\end{array}$ \\
\hline $\begin{array}{l}\text { Banheiros em significativo desacordo } \\
\text { com a norma de acessibilidade }\end{array}$ & Readequar os banheiros de acordo com a NBR 9050/2015. \\
\hline Piso com falhas e ondulações & Nivelamento e troca de todo o piso. \\
\hline $\begin{array}{l}\text { Falta de recursos (materiais e } \\
\text { medicamentos) }\end{array}$ & $\begin{array}{l}\text { Planejamento de estoque de medicamentos/materiais que atendam a } \\
\text { demanda existente. }\end{array}$ \\
\hline $\begin{array}{l}\text { Falta de conservação e } \\
\text { equipamentos quebrados }\end{array}$ & Planejamento de manutenção preventiva para os equipamentos. \\
\hline Rota de fuga com obstáculos & Liberar a circulação do corredor para a adequação da rota de fuga. \\
\hline Inexistência de extintor de incêndio & Providenciar o extintor e colocá-lo na área sinalizada. \\
\hline $\begin{array}{l}\text { Mobiliário não padronizado, } \\
\text { quebrado e desconfortável }\end{array}$ & $\begin{array}{l}\text { Reestruturação de todo o mobiliário para atender as necessidades dos } \\
\text { usuários, priorizando móveis com regulagem. }\end{array}$ \\
\hline $\begin{array}{l}\text { Inexistência de cadeiras para os } \\
\text { acompanhantes }\end{array}$ & $\begin{array}{l}\text { Aumentar o espaço para comportar cadeiras tanto na Sala de Espera quanto } \\
\text { na Sala de Infusão de Quimioterapia para os acompanhantes, observando } \\
\text { os espaçamentos entre elas e as áreas de circulação. }\end{array}$ \\
\hline
\end{tabular}

Fonte: autores (2019)

O mobiliário também precisa de manutenção e de novas aquisições, pois na maioria dos 
locais não há espaço adequado para a acomodação de pacientes nem de acompanhantes. 0 mobiliário dos postos de trabalho precisa de reestruturação para dispor de mais espaço para o desenvolvimento das tarefas e para o armazenamento de materiais e de objetos pessoais dos profissionais.

Já os banheiros dos pacientes, devem passar por uma reforma geral para atender aos requisitos de acessibilidade estabelecidos na NBR 9050/2015, já que são os locais mais problemáticos nessa questão. Em relação ao conforto ambiental (iluminação, ruído e temperatura), a deficiência na iluminação é um dos pontos que mais devem receber atenção, por ter sido o mais citado na análise da percepção dos usuários sobre o ambiente real, além de ter uma relação direta com a qualidade e a segurança das tarefas realizadas.

Cabe ainda uma consideração em relação a temperatura. Embora a NR-17 cite o índice de conforto entre 20 e 23 graus, prudente é considerar os estudos de Feitas, quando afirma:

Um indivíduo em um clima temperado ou frio pode sentir-se confortável entre 14 e $18^{\circ} \mathrm{C}$. Enquanto isso, um habitante de um clima quente e úmido, como em Recife - PE, só vai sentir a mesma sensação de bem-estar em temperaturas próximas a $25^{\circ} \mathrm{C}$, para desenvolver suas atividades sem maiores esforços de adequação ambiental (FREITAS, 2008, p.47).

Nesse sentido, nas adequações indicadas nas análises ergonômicas, se deve considerar peculiaridades como a citada acima. Além disso, mesmo aplicando a Constelação de Atributos apenas aos profissionais e não aos pacientes e acompanhantes, encontram-se ali elementos como ambiente agradável e acolhedor, denotando necessidades de buscar inserir esses atributos no ambiente.

\section{CONSIDERAÇÕES FINAIS}

Essa pesquisa insere-se em um conjunto de trabalhos de avaliação de ambientes, que vem sendo desenvolvido em um Hospital Universitário do Recife. Neste caso, possibilitou avaliar, no âmbito da Ergonomia, o Ambulatório de Oncologia do hospital foco destas abordagens, através da aplicação da MEAC, e identificar a necessidade de algumas intervenções no sentido de readequar esses espaços aos seus usuários e às atividades neles desenvolvidas, atendendo ao objetivo proposto.

De fato, entende-se a grande necessidade de adequações e ajustes relacionados a questões organizacionais, estruturais (sobretudo as de acessibilidade) e de conforto ambiental nesse local, onde pessoas com condições de saúde em situação de vulnerabilidade são submetidas a tratamento via de regra muito debilitador. Um ambiente mais favorável e ajustado a todas as necessidades aqui citadas, pode contribuir positivamente nos resultados dos procedimentos.

Espera-se que, por meio destas pesquisas, seja possível colaborar positivamente na melhoria das condições de trabalho e na satisfação das necessidades e expectativas de seus usuários. Assim, os resultados poderão comprovar que a Ergonomia contribui de forma decisiva para a qualidade de vida dos profissionais e dos outros usuários do local, além de impactar diretamente na qualidade da assistência prestada pelos profissionais no ambiente analisado. 


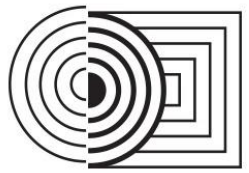

\section{$17^{\circ}$ ERGODESIGN \& USIHC 2019 \\ PUC-Rio, 11 a 13 de dezembro Rio de Janeiro, RJ, Brasil}

\section{REFERÊNCIAS}

ASSOCIAÇÃO BRASILEIRA DE NORMAS TÉCNICAS. NBR 10152: níveis de ruído para conforto acústico. Rio de Janeiro, 2000.

ASSOCIAÇÃO BRASILEIRA DE NORMAS TÉCNICAS. NBR 9050: Acessibilidade e edificações, mobiliário espaços e equipamento urbanos. Rio de Janeiro, 2015.

CIDADE, P.. Manual de ergonomia no escritório: 100 dicas para melhorar seu local de trabalho. Rio de Janeiro: Qualitymark, 2005, p. 81.

DEMO, G. et al. Políticas de gestão de pessoas no novo milênio: cenário dos estudos publicados nos periódicos da área de administração entre 2000 e 2010. RAM - Revista de Administração Mackenzie. São Paulo, v. 12, n. 5, p. 15-42, 2011.

ETTINGER, K. Direção e Produtividade. Direção, Organização e Administração de Empresas. Manual de Ensino 1. São Paulo, IBRASA, 1964.

FUNDAÇÃO JORGE DUPRAT FIGUEIREDO DE MEDICINA E SEGURANÇA DO TRABALHO (FUNDACENTRO). NHO 11: Avaliação dos níveis de iluminamento em ambientes internos de trabalho. São Paulo, 2018.

FRANÇA, A. C. L.. Práticas de recursos humanos - PRH: conceitos, ferramentas e procedimentos. 1 ed. - São Paulo: Atlas, 2010.

FREITAS, R. Entre mitos e limites: as possibilidades do adensamento construtivo face à qualidade de vida no ambiente urbano. Recife: Editora Universitária da UFPE, 2008.

HORTA, P.; DEMO, G.; ROURE, P. Políticas de gestão de pessoas, confiança e bem-estar: estudo em uma multinacional. RAC - Revista de Administração Contemporânea, Rio de Janeiro, v.16, n.4, p. 566-585, jul./ago. 2012.

INTERNATIONAL ERGONOMICS ASSOCIATION (IEA). What is ergonomics? Disponível em: $<$ https://www.iea.cc/whats/index.html>. Acesso em: 23 jul.2019.

KROEMER, K. H. E.; GRANDJEAN, E.. Manual de ergonomia: adaptando o trabalho ao homem. Porto Alegre: Bookman, 2005, p. 327.

LIMA COSTA, A. P.; VILLAROUCO, V.. Uso de escritórios panorâmicos em repartições públicas: um estudo de caso. Revista Ação Ergonômica, v. 7, n. 3, 2012.

MINISTÉRIO DA EDUCAÇÃO (MEC). Hospitais universitários: Disponível em: <http://portal.mec.gov.br/hospitais-universitarios>. Acesso em 28 jul. 2019.

MOLES, A. Sociodinámica de La cultura. Barcelona: Editora Gustavo Gili, 1968.

MONT'ALVÃO, C. A ergonomia do ambiente construído no Brasil. In: MONT'ALVÃO, C; VILLAROUCO, V. (org.). Um novo olhar para projeto: A Ergonomia no ambiente construído. Teresópolis: 2AB, 2011.

MORAES, A. M.; MONT'ALVÃO, C.. Ergonomia: Conceitos e Aplicações, Rio de Janeiro: 2 ab, 1998, p. 120.

SANTOS, V. B.. A percepção do clima organizacional dos serviços públicos sob a ótica da ergonomia: um estudo de caso nas recém-criadas Coordenações de Infraestrutura, Finanças e Compras da UFPE. Recife: UFPE, 2016.

VASCONCELOS, C. S. F. et al. Avaliação Ergonômica do Ambiente Construído: Estudo de caso em uma biblioteca universitária. Revista Ação Ergonômica, v. 4, n. 1, 2011.

VILLAROUCO, V. Construindo uma metodologia de avaliação ergonômica do ambienteAVEA. In: Anais do 14 Congresso Brasileiro de Ergonomia. Porto Seguro: ABERGO. 2008. 